\title{
Patient Education - Relevance in Nursing Education and Practice
}

\author{
Gunta Bēta* \\ Rīga Stradiņš University, Liepaja Branch, LV, Latvia \\ *Corresponding author: Gunta.Beta@rsu.lv
}

Received May 18, 2014; Revised June 16, 2014; Accepted June 17, 2014

\begin{abstract}
Working in health care, regardless of the care level provided by the establishment - primary, secondary or tertiary - a nurse must know and apply the competences and expertise in pedagogy. Theoretical knowledge and pedagogical skills are acquired within the educational process. The development of the pedagogical skills occurs according to the actual situation in the process of the nurse's practical work. Patient education includes general pedagogical coherence and is based on the structure of the educational process, the application of the means according to the patient's needs. Despite the e - learning opportunities that are being successfully applied in many areas, the patient's direct contact with nurses is important because the opportunity to have personal contact and get feedback is an advantage of direct communication that in the majority of cases is a personal and accurate way of communicating. The study analyzes the range of methods used by nurses in the education of patients that reflect the nursing activities in real situation, securing the process of development of formal education.
\end{abstract}

Keywords: cognition, education, communication, nurse, patient

Cite This Article: Gunta Bēta, "Patient Education - Relevance in Nursing Education and Practice." American Journal of Educational Research, vol. 2, no. 7 (2014): 441-446. doi: 10.12691/education-2-7-2.

\section{Introduction}

Each individual's health is a social, economic and personal development resource regardless of age, gender or cultural criteria. Health maintenance or preventional measures largely depend on the educational work that can be viewed not only in the perspective of nurses' work, but in the general context of the implementation of common public health strategy. Every individual's personal interest is also an important factor. Patient education as a process of interaction is topical in the context of any disease or prevention case. Quite often arriving to the health care institutions, especially hospitals, a patient feels as at the technological institution where the personnel works with very high, incomprehensible technologies. The role of a nurse as an educator here is very significant. She transfers to the patient a certain amount of appropriate and understandable information, reduces information deficit about the coming steps, promotes emotional stability and prevents the formation of cognitive dissonance. The patient's safety and well-being are created by a welcoming attitude and favorable atmosphere at various levels of patient care, when the patient's health problems or discomfort are understood. In general it can be described as a part of the treatment process service.

Patient education is an important but a complex issue. Nurses and doctors recognize the need for patient education. In the greatest number of cases the information that is important for the patient for the time being is outlined verbally or visualized, less focus is put on the secondary education aspects that are currently not in sight. The overall view of the situation is not less important because an educated patient is more engaged in solving problems, improving their health status, and future preventional measures. Educated, empowered patients and their relatives are active participants in maintaining health, forming an educated society.

\subsection{Aspects of Patient Education in the Training of Nurses}

Information gathering skills $[4,7,8]$ in the process of interaction with the patient (patient's subjective vision of the situation, the assessment of knowledge gained), the following transformation of the information obtained in the educational and patient care process are included in the training of nurses. Formal education, when acquiring the first level higher professional education, apart from free care philosophy involves also the acquisition of general philosophy, ethics and communication not only theoretically, but also working practically in groups dealing with study cases.

The implementation of the process of patient education as well as the application of the pedagogical principles in the training of nurses is defined by the Latvian Education Nursing professional standard in the sub-part - specific skills (paragraph 18) [20] defining the guidelines of educational skills, including the assessment of the patient's knowledge and skills in the field of health preservation and restoration. Patient knowledge and practical skills' assessment is defined in detail in the educational 
programmes for nurse training by the education authorities at the educational institutions.

The study process is systematized in such a way that at its beginning a health care specialist - a nurse could understand two important aspects. Firstly, the significance of health as a general value, taking into account that health is not just a personal value but should be viewed from a publicly moral, economic and even political perspective. Good health is not just a lucky phenomenon of a person, but the interaction of complex biological (sometimes genetic) and cultural factors. Secondly, they should learn to perceive health care as a dynamic, holistic process.

Successful outcome of the study process is formed not only of the future nurse professional conduct based on the synthesis of theoretical knowledge and practical skills, but the ability to build the context of an empathic attitude, including the creation of the therapeutic relationship [18], which includes a comprehensive awareness of a patient based on the feedback received.

The development of the study process from informative, regulatory process into a flexible, transformative learning process [1,2,9,12], not only lecturers but also students, sharing the responsibility, are involved in the democratic realisation of this process. Transformative approach to education is the basis for sustainable education, because it is based on a positive, critical and constructive approach to integration in the study process that develops step by step. A critical approach to patient education is inseparable from the content, process and prerequisites' reflection [9].

In any case, acquiring the professional skills that make up the nurse's competence,the motivation of the student's activity and behaviour, values that form the development of a future nurse are important. As noted by N. Geidžs [3]: "Motivation is a hypothetical internal process that gives energy and guides behavior." M. Puķīte [6] Analysing students' pedagogical competences in the study process, says: "Competence is formed, gaining knowledge, acquiring skills and developing a responsible attitude." The acquisition of interdisciplinary knowledge forms the development of a variety of competences and expertise.

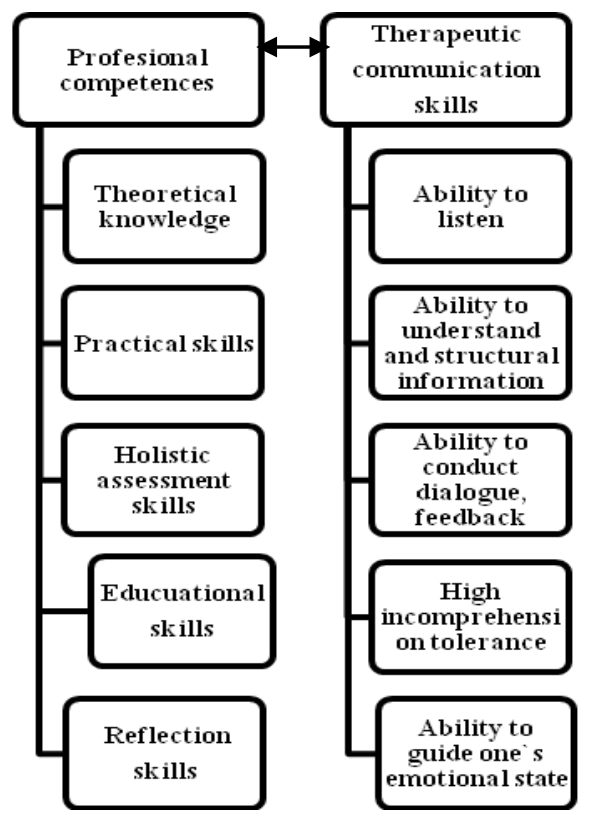

Figure 1. A set of competences for the progressive nurse-patient cooperation (C)
The set of theoretical knowledge as well as practical and communicative skills acquired by nurses is based on the platform of personal responsibility and understanding of values, including the nurse's practical skills in educating patients are the essential parameters of the professionalism of nurses that will determine the future career opportunities.

Students, after the acquisition of the theoretical material and dealing with case studies, acquire the patient education methodology where the alternatives vary. Ability to recognize non-verbal communication's physical and emotional expression, to understand the positive verbal communication stratagies as well as identify the significance of the patient education development strategy is the part of the professionalism of future nurses in the context of the pedagogical aspect. Communication skills the ability to listen, to form open questions, to conduct a dialogue - often form one of the leading aspects in the patient care management and patient education.

\subsection{Aspects of Patient Education in Nurse Practice}

The range of nurses' educational activities includes patient education about the prevention of various diseases, basics of professional activities as well as practical issues. The information provided by the nurse within the process of interaction may be both informative and educational. Patient education can be a spontaneous response to the issues raised by the patient, or it can be planned in advance. The boundaries of the transition from information to the educational sphere are not restricted.

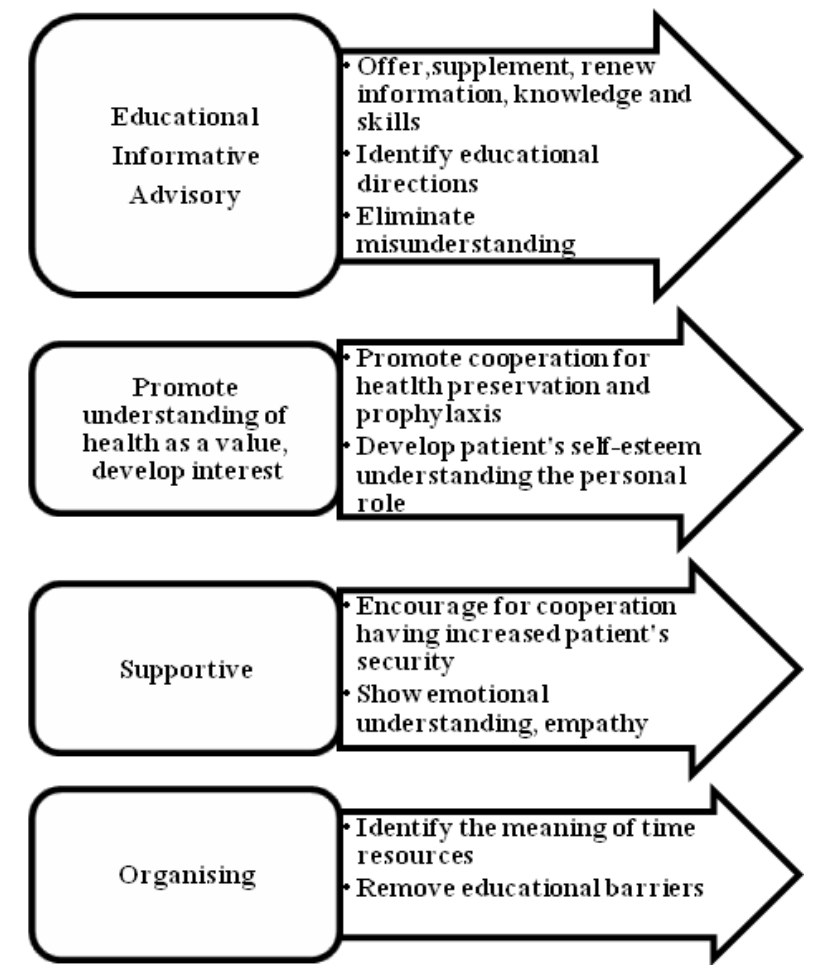

Figure 2. Directions of educational work of nurses in cooperation with patients (C)

Psychological, sociological, anthropological and ethical aspects are important in patient education. The understanding of those, identifying each patient as a phenomenon, demonstrating positive collaboration, 
flexible interface, the ability to structure educational information, as well as offering alternative solutions form an informed nurses' educational activities` paradigm.

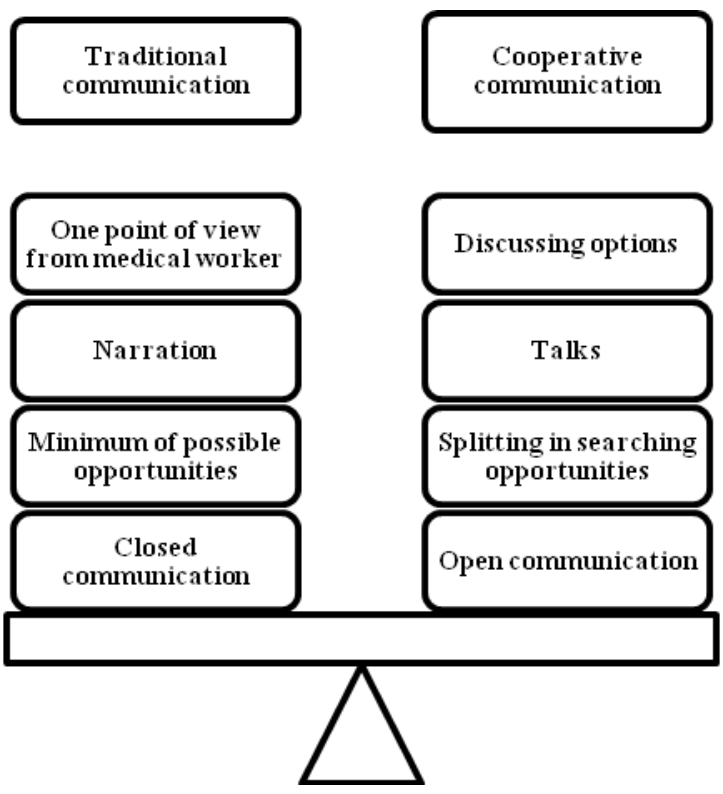

Figure 3. Traditional and cooperative communication in the process of patient education (adapted acc McCabe, C., Timmins, F.)[8]

Undoubtedly, in the process of patient education a nurse must be able to guide her own emotional state and orient the patient to open and positive communication and cooperation in order to promote both the understanding of the situation and the strategical awareness how to maintain and foster health in future.

The patient educational process relevant to the patient's level of understanding, comprehensive, delivered at the appropriate time, as well as designed to understand can be one of the prerequisites for the patient to get some inspiration to change attitudes, increase motivation and awareness of the importance of co-responsibility to make decisions about medical treatment, the patient's behaviour or change of habits. Nurses' professional communication adjusted to the case is able to ensure a high level of patient trust and cooperation that is of great importance in prevention, but particularly in the treatment process. The nurse provides information, educates without making judgments, allowing patients to decide for themselves except acute situations. The author has adopted the model for professional nurses' activities area where the role of a nurse conducting patient education is reflected diversly, indicating the range of possibilities, making an appropriate decision.

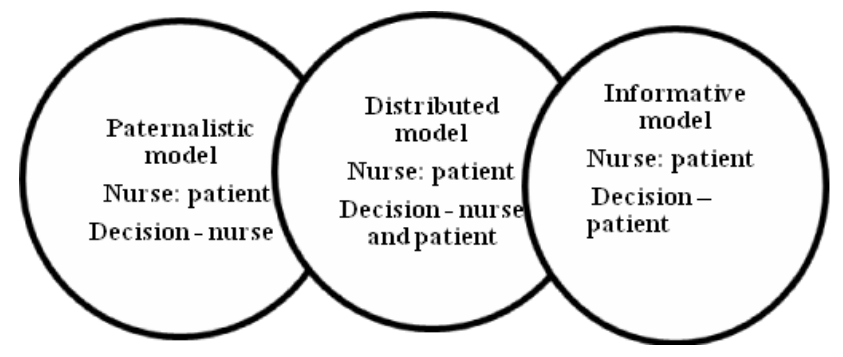

Figure 4. Three models of making decisions in the medical treatment process in interaction (adapted acc.to Charles et al., \& Chalamon, I., Chouk, I., Heilbrunn, B.) $[10,11]$
When you create a positive communication patients prefer to engage themselves in joint decision-making that is based on comprehensive information, and education and is related to the patient's satisfaction. Education, counsleling process and the result of the patient's judgment are connected with the value priorities of the patient, possible or impossible changes in the patient's life that are also largely determined by the patient's future course of action.

The nurse's understanding of the educational process plays a really important role in the evaluation. Has the patient understood what was said? What causes difficulties for a patient? Should the educational process be repeated? These issues include both the feedback, identifying the patient's level of understanding and integration of reflection in society, in the educational process. The nurse, who demonstrates the ability to respond to patients' questions not with abstract concepts, but concrete examples, is able to clearly clarify the priorities to the patient, is able to appeal to their coresponsibility for health as well as analyze her performance, is an important supportive and educational resource of a definite case. It should be noted that the educational dimension contributing to the sociopsychological sphere of development, helping the patient to develop a new perspective is rather more complicated than educating about practical activities.

In order to ensure the patient's range of perception it is recommended to expand the range of educational tools because each person perceives information and events in different ways. Different barrier impact on the patient's health, age, cultural differences and language barriers are possible. A nurse should evaluate the applied educational methods and tools to the corresponding situation (audio, visual, tactile, kinesthetic teaching), keeping in mind that a healthy person remembers $10 \%$ of what he/she has read, $20 \%$ of what he/she has heard, $30 \%$ of what was spoken or written, $50 \%$ of what he/she has heard and seen, $70 \%$ of what is being said, and $90 \%$ of what is being said and done. The figures are different for each individual, but they reflect the tendencies of the adaptation of information.

It is possible to connect verbal education with an emotionally perceived educational type (case study), practical action, which is sometimes more effective than the general theoretical one. A written or visual (posters, CDs, video) patient education mode could be used as an additon to the given verbal information.

A wide spectrum of activities of a nurse as an educator is focused on the case and the desired outcome. Patient education process can be affected by both the patient's expressed wishes about the information they want to receive and by the nurse's personal views on the necessary information priorities: what, when, and what kind of information should be delivered to patients.That information may not always be adequate to patients' preferences.

\section{Methodology}

Motivation of the research: the nurses have voluntarily attended a formal education course that was free of charge. They have acquired the 1st level higher education, having improved the earlier (until 2004) acquired 3rd level 
professional education ISCED (International Standard Classification of Education) to the 4th ISCED professional level.

Subjects of the study programme - pedagogy, requirements for the graduation paper - to reflect in a written way how a nurse conducts a free chosen patient education case study connecting it to her own pedagogical activities.

Aim of the research: identify the patient education tendencies in nurses' self-reflection using a qualitative research method.

\section{Tasks of the research:}

1. To conduct a qualitative study analyzing the nurses' graduation papers in pedagogy (2012/13 academic year).

2. Analyze the patient education methods defined by the nurses that reflect an understanding about the patient education.

\section{Procedures}

In the qualitative analysis of work the tendencies of nurses' practical educational work have been clarified, noting patient education by nurses indicated methods and provision of the feedback in the educational process.

The graduation papers were selected at random. Total number $(\mathrm{n}=140)$.

Statistical data analysis was performed using SPSS v.17.0 software and Microsoft Office Excel v.11.

\section{Results}

The analysis of the study data (see results in Tables A and B) shows that nurses conduct patient education only verbally by defining the types of information delivered in the patient education process: tell, educate, inform (100\%). It could be concluded that in most cases patient education occurs giving information, which is not the most effective method of education. It is evident from the small amount of the marked answers that in the process of patient education discussion takes place - 24, 3\% (Mean 0.24). Discussion is organized using open questions as well as empathy on the nurse's part in the process of communication at the time of the patient education process.

\begin{tabular}{|c|c|c|c|}
\hline & $\mathrm{N}$ & Mean & Std. Deviation \\
\hline & Statistic & Statistic & Statistic \\
\hline Educated, informed & 140 & 1,00 & ,000 \\
\hline Discuss & 140 & ,24 & ,430 \\
\hline Writen materials & 140 & ,09 & ,281 \\
\hline Demonstrations & 140 &, 06 & ,246 \\
\hline Role play & 140 & ,00 & ,000 \\
\hline Electronic resources & 140 &, 01 & 119 \\
\hline Feedback & 140 & ,29 & 453 \\
\hline Valid N (listwise) & 140 & & \\
\hline
\end{tabular}

Additional educational tools that help to ensure a full understanding on the patient's part and improve patient education strategies, are really used in the graduation papers. Electronic resources that provide appropriate learning topics' in-depth visual and auditory perception are used only in $1.4 \%$ cases (Mean - 0.1). Working with
Internet resources and the computer was defined in the graduation papers mostly referring to when a nurse indicates the address where one can find relevant information rather than focus on the activity- who, what and how.

Table 2. Reflection of document analysis B

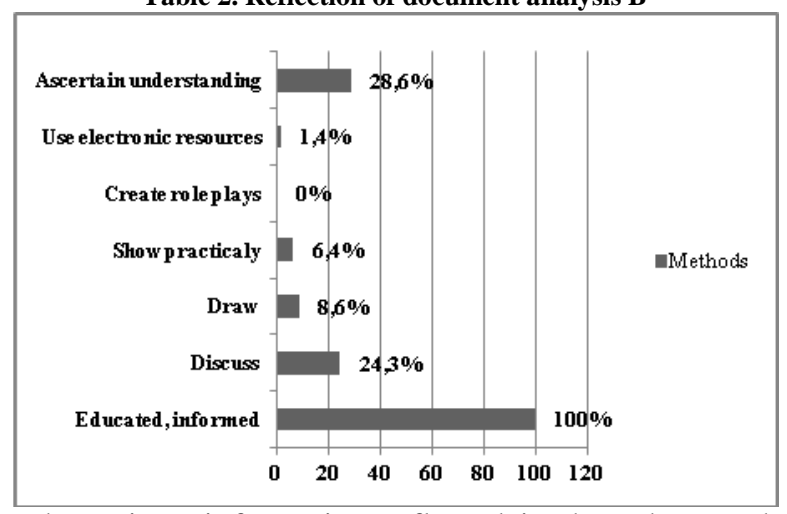

The written information reflected in the schemes that helps the patient to visualize and understand the information provided that the patient can re-read or look at later, is used only in 8.6\% cases (Mean - 0.9).

The figures for providing feedback, while making sure that the patient has understood the information, are presented in $28.6 \%$ cases (Mean - 0.29). The results are similar to the EU's Eurobarometer survey data [19], where it is stated that the time allocated by health care workers, including nurses, in Latvia to a patient as well as feedback as a performance instrument are factors that were defined as insufficient. Role-games as one of the possible methods of patient education are not defined by nurses in their practical work.

\section{Discussion}

Considering the results obtained, it can be concluded that two factors mismatch: the knowledge gained during the education process is not fully integrated into practice. If nurses have within the framework of the education process further added to their knowledge in pedagogy, then the most knowledge has been transferred to the philosophical (theoretical) aspect without increased specific practical knowledge updating, mostly informative rather than transformative.

An important factor for the teachers involved in the education of nurses and future nurses is to have practical experience in patient care. Fiddler M. note: "The nurse is an expert who can evaluate and focus herself on the critical factors in a situation" [5], learning on the experience-based practice she can provide colleagues, nurses with full understanding how to ensure patient education and integrate it in work. The teaching staffs in this specified educational process for nurses, who raise their educational level, were experienced nurses. It should be noted, however, that such a practice is not always provided. Occasionally, but mostly it refers to the future nurses' education process, specialists with only pedagogical education without medical experience are involved to deliver pedagogical knowledge to nurses. The reason for such cases in various parts of the programme implementation is the limited number of nurses - experts who are willing to participate in the education of students 
during their pre-clinical practice, as well as economic factors that limit the opportunity to involve additional nurses from the field practice instutions in the educational process. The nurses from the field practice institutions can become a complementary part of the system while, at the same time, developing an inter-institutional cooperation model.

In health care, as it is in other sectors, errors come from insufficient, improper communication and information deficit $[15,17]$. Communication is a heart of patient education. Error versatility can influence the process of treatment. Inadequate patient education can create a Swiss cheese model [16] that directs away from the working strategy without mistakes and may cause the following: 1. Instead of promoting patient understanding comes additional patient confusion;

2.Erroneous information is obtained from other sources;

3. To promote the formation of unwanted side-effects;

4. To prolong the recovery process.

Patient information deficiency in the treatment process and the home or ambulatory care settings, could be solved with the help of nurses. Half of the patients in the period after they have left the hospital make at least one error in the use of the prescribed medication [14].

A nurse is regarded as a skilled and responsible work performer. According to the Fr. Herzberg theory [13], dissatisfaction with the job can be caused by the processes of the organization and management of work, job security, status and salary. These are considered as hygiene factors. Similarly, a negative impact on work processes can be caused by motivational factors: growth opportunities, recognition deficit. Uniformity of educational work and gaps reflected in the graduation papers could be caused by the chronically disorganized system of work organization, a large number of patients and intensive work. A lot of nurses do not see an opportunity to work in a different way and they reflect this in their graduation papers.

Insufficient patient education process could be caused also by human factors [15]: nurses' cognitive overload, stress and fatigue, as well as poor (nurse - patient) communication factors.

\section{Conclusions}

It could be concluded that the study process in pedagogy for nurses has been mainly informative, because, analysing the graduation papers of nurses in pedagogy, a positive representation of a transformative learning process, based on the meta-cognitive skills' integration (to plan, conduct, forsee, check - feedback and appreciate - to reflect ) is observed fairly little.

Randomly selected graduation papers reflect relatively low understanding of professional values (patient / person - value) where the patient's desire to get comprehensive information is not always fulfilled, mostly filling an information niche. Without receiving feedback, which is an advantage of direct communication, the assessment of the information given to the patient lacks. This assessment can be viewed as a part of the content, process and premise reflection. Nurses' activity in educating patients is mainly focused on the goal rather than on the result. The nurses can not fully integrate the knowledge acquired of patient education in their work process description, they do not form a new activity paradigm. Reflection of the situation in the graduation papers confirms the strong oneway patient education traditions that are contradictory with the principles of comprehensive patient education and partly refer to the actual situation in patient care and patient education. The results obtained suggest that there are both latent and visible chronic work organization errors that had a destructive impact during the nurses' practice period. The latter have influenced the nurses' understanding about patient educational work. These errors can not be identified in the qualitative analysis of documents.

According to the author's point of view, the spectrum of patient education inhibitory reasons can appear in the process of the future research, surveying on patient education work. The nurses' point of view not only on educational methods used, but also on the factors that cause distraction in educational work was clarified.

The result that a small number of nurses confirm comprehensive patient education platform understanding, shows the need for more informal education course in practical methodology for patient education. The course should contain a practical possibility for integration and an opportunity for nurses to form patient educational situation, to demonstrate and evaluate it in an intellectual and practical way, promoting a positive change in the nurse`s critical thinking and action.

\section{References}

[1] Benner, P., Supthen, M., Leonard, V.,\& Day, L. (2010) Educating nurses: A call for radical transformation. San Francisko, CA: Jossey-Bass.

[2] Briede B., Pēks L. (2011) Ecological approach in education. Series Educational Ecology, Jelgava. LLU, IMI.

[3] Geidžs N.L./ Berliners D.C. General Pedagogy. Riga: Zvaigzne ABC, 1999.662 pp.

[4] Silverman, J., Kurtz, S. and Draper, J. (2005) Skills for Communicating with Patients. Oxford: Radcliffe Medical Press.

[5] Taylor, K., Marienau, C., \& Fiddler, M. (2000). Developing adult learners: Strategies for teachers and trainers. San Francisco: Jossey-Bass Inc., Publishers. 59-66.

[6] Puksite M. (2012) Formation of medical students' pedagogical competences in the study process. $\mathrm{PhD}$ Thesis Riga, Latvian University.

[7] Kraszewski, S, McEwen, A. (2010) Communication Skills for Adult Nurses.Open University Press McGraw-Hill.

[8] McCabe, C. and Timmins, F. (2006) Communication Skills for Nursing Practice. Basingstoke:Palgrave Macmillan.

[9] Mezirow, J. (1991). Transformative dimensions of adult learni ng. San Francisco: Jossey - Bass. Avaible: http://www.esludwig.com/uploads/2/6/1/0/26105457/transformati ve-learning-mezirow-1997.pdf.

[10] Chalamon, I., Chouk, I., Heilbrunn, B. (2010) Typology of Patients` Expectations towards the Health-Care System: A Semiotic Approach. Avaible: http://www.iae.univ-

lille1.fr/SitesCongres/JIMS/images/1_Chalamonchoukheilbrunn.p df.

[11] Charles C, Gafni A, Whelan T. (1999) Decision-making in the physician-patient encounter: revisiting the shared treatment decision-making model. Soc Sci Med 49:651-61.

[12] Elliott, J. (2010) Insights to Transformative learning through Education for Sustainable development. Learning and Teaching in Higher Education, Issue 5, 96-113.

[13] Hercberg, F. (1968) One More Time: How do you Motivate Employees? Harvard Business Review. 2003 jan; 81 (1): 87-96.

[14] Kripalani S, Roumie CL, Dalal AK, et al. (2012) Effect of a Pharmacist Intervention on Clinically Important Medication Errors 
after Hospital Discharge: A Randomized Trial. Ann Intern Med. 3 July.

Avaible http://www.ncbi.nlm.nih.gov/pmc/articles/PMC3575734/.

[15] Leonard, M., Graham, S. Bonacum, D. The human factor: the critical importance of effective teamwork and communication in providing safe care Quality and Safety In Health care. 2004 october; 13 (Suppl 1) 185-190.

Avaible: http:/qualitysafety.bmj.com/content/13/suppl_1/i85.long

[16] Perneger, Th,(2005)The Swiss cheese model of safety incidents: are there holes in the metaphor? Published: BMC Health Services Research 2005, 5: 71. Avaible: http://www.ncbi.nlm.nih.gov/pubmed/16280077.

[17] Pronovost, P., Berenholtz, S., Dorman,T, Lipsett,P., A., Simmonds, T, and Haraden C. (2003) Improving Communication in the ICU
Using Daily Goals Journal of Critical Care, Vol 18, No 2 (June), pp 71-75.

[18] Rosenberg, S, Gallo-Silver, L, (2011) Therapeutic communication skills and student nurses in the clinical setting. Teaching and Learning in Nursing 6, 2-8.

[19] Eurobarometer Qualitative Study PATIENT INVOLVEMENT Aggregate Report, 2012

http://ec.europa.eu/public_opinion/archives/quali/ql_5937patient_ en.pdf.

[20] Nursing profession standard. Ministry of Education Science, Latvija, 2003.

Avaible: http://www.niid.lv/files/prof_standartu_registrs/Masa.pdf. 